\title{
Modern Contraceptive Utilization and Associated Factors among Married Gumuz Women in Metekel Zone North West Ethiopia
}

\author{
Alemnew Ashagrie Adane, ${ }^{1}$ Yibeltal Alemu Bekele $\mathbb{B D}^{2}$ Ergoye Melese, ${ }^{3}$ \\ Getasew Taddesse Worku, ${ }^{4}$ and Henok Biresaw Netsere ${ }^{5}$ \\ ${ }^{1}$ Department of Epidemiology and Biostatistic, Pawi Health Science College, Ethiopia \\ ${ }^{2}$ Department of Reproductive Health and Population Studies, School of Public Health, Bahir Dar University, Bahir Dar, Ethiopia \\ ${ }^{3}$ Department of Epidemiology and Biostatistic, School of Public Health, Bahir Dar University, Bahir Dar, Ethiopia \\ ${ }^{4}$ Department of Health Service Management and Health Economics, School of Public Health, Bahir Dar University, \\ Bahir Dar, Ethiopia \\ ${ }^{5}$ Department of Nursing, School of Health science, Bahir Dar University, Bahir Dar, Ethiopia
}

Correspondence should be addressed to Yibeltal Alemu Bekele; yibeltalalemu6@gmail.com

Received 27 January 2020; Accepted 3 June 2020; Published 23 July 2020

Academic Editor: Alessandro Favilli

Copyright (c) 2020 Alemnew Ashagrie Adane et al. This is an open access article distributed under the Creative Commons Attribution License, which permits unrestricted use, distribution, and reproduction in any medium, provided the original work is properly cited.

\begin{abstract}
Background. Modern contraceptives are a key intervention to improve the health of both the mother and children by preventing unintended pregnancy. However, significant numbers of women were facing abortion-related morbidity and mortality globally including Ethiopia due to the nonuse or failure of contraceptive uses. Therefore, the aim of this study was to assess the utilization of modern contraceptive methods and associated factors among married Gumuz women in Metekel Zone North West Ethiopia. A community-based cross-sectional study was conducted among 580 women from March 1 to 30/2019. Pretested structured interview administer questionnaires was used to collect the data. Data were cleaned, coded, and entered into Epi-info version 7.1 and export to SPSS for farther analysis. Both bivariate and multivariate analyses were used. On bivariate analysis $P$ value, less than 0.2 were used to select the candidate variable for multivariate analysis. $P$ value and $95 \%$ confidence interval were used to measure the level of significance on multivariate analysis and those variables whose $P$ value $<$ 0.05 were considered as statically significant. The prevalence of modern contraceptive method was $18.6 \%$ [95\% CI: 15.00-22.00]. Age $\geq 35$ year AOR 4.67; 95\% CI (1.34 -16.18), able to read and write AOR 6.45 95\% CI(2.98-13.97), primary school AOR 6.56; 95\% CI (2.22-19.38), secondary school AOR 7.27; 95\% CI (3.00-17.61), counseled on contraceptive methods AOR 3.72 95\% CI (2.11-6.56), moderate knowledge on modern contraceptive method AOR 2.31; 95\% CI (1.15-4.64), and good knowledge on modern contraceptive method AOR 4.37; 95\% CI (2.38-8.02) were identified as statistically significant with modern contraceptive methods utilization. The prevalence of contraceptive utilization was low when compared to the national and the regional figure. Maternal age, maternal educational status, counseling about modern contraceptive methods, and knowledge on modern contraceptive methods were found as statistically significant with modern contraceptive utilization.
\end{abstract}

\section{Background}

Family planning (FP) is defined as the ability of individuals or couples to anticipate and attain their desired number of children, the spacing, and timing of their births [1]. In this concern, the modern contraceptive method key decides couples to have sexual intercourse at any time [2]. Nowadays, more attention is being given for family planning because of their multiple benefits to improve both the health of children and woman's by reducing the risk of unintended pregnancies. Family planning is one of the main interventions to reduce maternal and neonatal morbidity and mortality $[3,4]$.

World Health Organization (WHO) report indicates that using modern contraceptive can reduce $32 \%$ of all maternal death and nearly $10 \%$ of childhood deaths [5]. It is also 
estimated that $90 \%$ of the abortion-related and $20 \%$ of the pregnancy-related morbidity and mortality can be prevented with the use of effective family planning methods [6]. However, 225 million women who want to prevent or delay pregnancy but face significant barriers to obtaining and using modern contraceptive methods that meet their individual needs [7].

Globally, the trends of modern contraceptive utilization have increased slightly, which was $54 \%$ in 1990 to $57.4 \%$ in 2015. While in Africa, the trends of modern contraceptive utilization have ascended a little, which increases from $23.6 \%$ in 2008 to $28.5 \%$ in 2015 [8, 9].

Studies conducted in Asia show that the magnitudes of modern contraceptive utilization among married women were $36 \%, 81.27 \%$, in Nepal and Bangladesh, respectively $[10,11]$. Similarly, studies in Africa show that the magnitudes of modern contraceptive utilization were $39.9 \%, 32 \%, 31 \%$, and $92.7 \%$ in South Africa, Baringo Kenya, and Nigeria, respectively [12-14]. In addition, different literature conducted in Ethiopia also shows that the prevalence of modern contraceptive utilization ranges from 9.1\%-46.9\% [15-22].

Studies conducted in developing countries showed that the age of the respondent, education status of the respondent, parity, religion, marital status, knowledge about modern family planning method and side effects, method approval by self and partners, and employment status were factors for the utilization of contraceptives [23-25]. Similarly, studies in Ethiopia shows age, residence, educational status of the mother, couple discussion, perceived husband approval, discussion with health extension workers, perceived cultural acceptance, the desire of more children, monthly income, and numbers of living children were determined by modern family planning method utilization $[15,17,19,20]$.

According to the Ethiopian mini demographic health survey, the 2019 report indicates that the contraceptive prevalence rate was $41 \%$ while the 2015/16 Ethiopian health sector transformation plan was planned to achieve contraceptive prevalence rate to $55 \%$ in $2019 / 20$ [26, 27]. There is some increment on contraceptive prevalence rate while the increment was not sufficient enough to achieve the country planned in 2019/20 on the area of health sector transformation plan.

There are few studies about prevalence and associated factors of modern contraceptive utilization among married Gumuz women. But these studies were fragmented and not context-specific in the study area because Gumuz ethnic is one of the pastorals groups in Ethiopia. Therefore, this study was conducted to determine the magnitudes and associated factors of modern contraceptive utilization among married Gumuz women.

\section{Methods and Materials}

2.1. Study Area. Metekel zone is one of the three zones found in Benishangul Gumuz Regional State, located $570 \mathrm{~km}$ Northwest of Addis Ababa. Administratively, the zone is structured into seven districts that are (Pawie, Mandura, Wombera, Debati, Bullen, Dangur, and Guba), having 7 urban and 97 rural villages. Based on the 2007 E.C Ethiopian census, the total population of the zone was estimated to be 276,367 , of whom 139,119 were men and 137,248 women.
The majority of 238,752 of the population live in rural areas and economically dependent on farming. Gumuz is the majority ethnic group in the zone followed by Shinasha. The zone has seven hospitals, 13 health centers, and 76 health posts.

2.2. Sample Size Determination and Procedures. The sample size was calculated through a single population proportion formula. The proportion of women utilization of family planning services this study used was $64.6 \%$ [28], with the consideration of a margin of error of $5 \%$, nonresponse rate of $10 \%$, and design effect of 1.5. The final total sample size was 580 women. A multistage sampling method was used. A total of nine Gumuz villages was included in the zone selected randomly from the seven districts. A preliminary survey was conducted to identify married women in the zone. Finally, a simple random sampling technique was used to identify each participant in each selected village. The number of respondents in each village was assigned proportionally.

2.3. Variables of the Study. Dependent Variable: Modern contraceptive utilization means utilizations of any modern contraceptive methods during the data collection period (Yes/No).

Independent Variables were categorized into four themes. Sociodemographic variables: Age, education, religion, and occupation. Reproductive health-related variables: Gravidity, parity, birth interval, desired number of children, and family size. Individual-related variables: Knowledge of FP, attitude towards FP, and couples' decision about FP. Health facilityrelated variables: Choice of FP method, counseling on contraceptive method, and distance of health facility.

2.4. Operational Definition. Knowledge about modern family planning method: Based on bloom cutoff point those reproductive-age women who answered 75-100\% 50-74\%, and $<50 \%$ from seven knowledge assessing questions were considered as having good knowledge, moderate knowledge, and poor knowledge, respectively.

Attitude towards modern contraceptive methods: Based on the bloom cutoff point, those reproductive-age women who answered $75-100 \%, 50-75 \%$, and $<50 \%$ from eight attitude assessing questions were considered as having a positive attitude, neutral attitude, and negative attitude, respectively.

2.5. Data Collection Tools and Procedures. The questionnaire was developed by reviewing different literature. It was first prepared in English and translated into Amharic then translated back to English to check for consistency. Data were collected via interview. Trained health extension workers one in each village with three supervisors those were nurses were assigned for data collection along with the principal investigator.

2.6. Data Quality Controls. The questionnaire was pretest with $10 \%$ (58) of the sample population incomparable district. Amharic versions of the questioner were used to collect the data. Two-day training was provided for the data collectors and supervisors on the objectives and purposes of the study. The supervisors have supervised the data collection process every day and the principal investigator also cheeks the collected questionnaire for completeness every other day. 
TABLE 1: Sociodemographic characteristics the respondents in Metekel zone, Benishangul, Ethiopia, $2019(n=580)$.

\begin{tabular}{lccc}
\hline Variables & Category & Frequency & Percent (\%) \\
\hline \multirow{4}{*}{ Age } & $15-24$ & 34 & 5.9 \\
& $25-34$ & 403 & 69.5 \\
& $\geq 35$ & 143 & 24.6 \\
\hline \multirow{4}{*}{ Religion } & Orthodox & 87 & 15 \\
& Muslim & 64 & 11 \\
& Protestant & 92 & 16 \\
& Catholic & 108 & 18.6 \\
Occupation & Pagan & 228 & 39.4 \\
\hline \multirow{4}{*}{ Educational } & Farmer & 511 & 88.1 \\
& Government employee & 43 & 7.5 \\
level & House wife & 20 & 3.4 \\
& Student & 6 & 1 \\
\hline & Primary school (1-8) & 19 & 3.3 \\
& Secondary school (9-12) & 35 & 6 \\
\hline
\end{tabular}

2.7. Data Processing and Analysis. Data were cleaned, coded, and entered into Epi-info version 7.1 then exported to SPSS version 23 for further analysis. A descriptive analysis was carried out to see the distribution of independent variables. Binary logistic regression was used to examine associations between the dependent variable and independent variables. In the bivariate analysis, those variables whose $P$ value less than 0.25 was used to select the candidate variable for multivariate analysis. Multicollenearity test was performed via a variance inflation factor before fitted to the final model. $P$ values $<0.05$ with $95 \%$ confidence interval was used to determine the level of significance on multivariable analysis. Hosmer and Lemeshow test were used for checking the model fitness for logistic regressions at $P$ value $>0.05$.

\section{Results}

3.1. Sociodemographic Characteristics. A total of 580 married women participated. Four hundred three (69.5\%) of the participants were in the age group of 25 to 34 years with the mean age of $32.79(\mathrm{SD} \pm 5.53)$. Four hundred eighty-three $(83.5 \%)$ of the respondents were not able to read and write, while only $54(9.3 \%)$ of the respondents attained formal education. Five hundred eleven (88.1\%) respondents were farmers. Two hundred twenty-eight (39.4\%) respondents were followers of pagans (Table 1).

3.2. Reproductive History. Three hundred twenty-four (55.9\%) respondents were married before the age of 15 years. Two hundred seventeen-nine $(48.1 \%)$ respondents had planned to have an additional child within 2 years periods. One hundred twenty-nine (22.2\%) respondents had discussed on contraceptive methods with their partners. Four
TABLE 2: Reproductive health characteristics of the respondents in Metekel zone, Benishangul, Ethiopia, 2019.

\begin{tabular}{|c|c|c|c|}
\hline Variable & Category & Frequency & Percent (\%) \\
\hline \multirow{3}{*}{ Age at first marriage } & $<15$ & 324 & 55.9 \\
\hline & $15-18$ & 254 & 43.8 \\
\hline & $>18$ & 2 & 0.3 \\
\hline \multirow{3}{*}{ Gravidity } & Prime gravid & 15 & 2.6 \\
\hline & Multigravid & 371 & 64 \\
\hline & Grand multi-Para & 194 & 33.4 \\
\hline \multirow{3}{*}{ Parity } & Prime Para & 11 & 1.9 \\
\hline & Multi-Para & 364 & 62.8 \\
\hline & Grand multi-Para & 205 & 35.3 \\
\hline \multirow{2}{*}{ Age at first birth } & $15-19$ & 557 & 96.0 \\
\hline & $20-24$ & 23 & 4.0 \\
\hline \multirow{2}{*}{$\begin{array}{l}\text { Plan additional } \\
\text { children within } \\
2 \text { years }\end{array}$} & Yes & 279 & 48.1 \\
\hline & No & 301 & 51.9 \\
\hline \multirow{3}{*}{$\begin{array}{l}\text { How many alive } \\
\text { children }\end{array}$} & 1 & 10 & 1.7 \\
\hline & $2-4$ & 369 & 63.9 \\
\hline & $\geq 5$ & 201 & 34.7 \\
\hline \multirow{2}{*}{$\begin{array}{l}\text { Discussed with } \\
\text { partners on } \\
\text { contraceptive } \\
\text { method }\end{array}$} & Yes & 129 & 22.2 \\
\hline & No & 451 & 77.8 \\
\hline \multirow{3}{*}{$\begin{array}{l}\text { Decides number } \\
\text { of children }\end{array}$} & Husband & 417 & 71.9 \\
\hline & Wife & 83 & 14.3 \\
\hline & Both & 80 & 13.8 \\
\hline
\end{tabular}

hundred seventeen (71.9\%) respondents said that only partners decided the numbers of their children (Table 2).

3.3. Individual Related Factors. Two hundred eight (46.2\%) respondents had heard about family planning methods. Three hundred eighty (65.5\%) respondents had had poor knowledge, 99 (15.4\%) respondents had had moderate knowledge, and 111(19.1\%) respondents had had good knowledge about contraceptives methods. The most commonly mentioned methods by respondents were injectable $158(27.1 \%)$, oral contraceptive pills 119 (20.4\%), and condom 103 (17.7\%) (Table 3).

3.4. Prevalence of Current Utilization of Modern Contraceptive Methods. The overall utilizations of modern contraceptive utilization were 108 (18.6\%). Among currently using modern contraceptive method seventy-three (12.6\%), 20 (3.4\%), and $15(2.6 \%)$ respondents were using the injectable method, oral contraceptive pills, and implants, respectively. One hundred five (18.1\%) respondents who were got a choice modern contraceptive method.

3.5. Factors That Associated with Current Utilization of Modern Contraceptive Methods. In the bivariate analysis, maternal education, age, occupation, parity, number of living 
children, couple discussion, knowledge of FP, and counseling on contraceptive method were candidate variable for multivariate analysis at $P$ value 0.25 . And on multivariate analysis, maternal education, ages, counseling on contraceptive methods, and knowledge about FP were factors associated with modern contraceptive methods at the $P$ value less than 0.05 .

The odds of modern contraceptive utilization among women who attained primary school and secondary education were 7 times more likely to utilize modern contraceptive methods than those cannot read and write $(\mathrm{AOR}=6.56 ; 95 \%$ CI: 2.22-19.38) and (AOR $=7.27$; 95\% CI: 3.00-17.61), respectively. The odds of modern contraceptive utilization among women whose age was $\geq 35$ was 5 times more likely to utilize modern contraceptive methods than those women whose ages 15-24 (AOR $=4.67 ; 95 \%$ CI: 1.34-16.18). Women who had been counseled on modern contraceptive methods were 4 times higher than those women who did not counsel on modern contraceptives (AOR $=3.72$; 95\% CI: 2.11-6.56). Women who had good knowledge on modern contraceptive methods were 4 times higher than those women who had poor knowledge (AOR $=4.37$; 95\% CI: 2.38-8.02) (Table 4 ).

\section{Discussion}

The prevalence of modern contraceptive utilization was $18.6 \%$ with $95 \%$ CI [15.00-22.00]. This finding of this study was in line with the studies conducted in the Bale eco region Ethiopia 20.8\% (11). However, the finding of this study was lower than studies conducted in Ethiopia and Benishagule Gumuz coverage of FP (35\%) and (28\%), respectively [27], and Kenya $51 \%$ [28]. The discrepancy might be due to sociodemographic differences between the study areas. In this study, only $9.3 \%$ of respondents attained formal education; it is lower than the national level, around $59.5 \%$ attained formal education [29]. Similarly, 93\% of women attained formal education in Kenya [30]. In addition, access to media may increase the utilizations of modern family planning method utilization, while in this study, only $1.2 \%$ of women has access to media [31].

The findings of this study show that mothers who had had knowledge about modern family planning were more likely to use family planning services than those who had poor knowledge. This finding was consistent with studies conducted in Tigray, Dabat, and in Farta district [20-27, 32 , 33]. This might be due to the knowledge about the modern family planning method is the key means of understanding the prone and cons of each method and decrease the complaints. In addition, knowledge on family planning method decreases the myth related to modern family planning methods and increases the uptakes of modern family planning methods [34].

Mothers who had been counseled on modern contraceptive methods in the health facility were more likely to use modern contraceptive than mothers who had never been counseled. This finding was in line with the findings of previous studies conducted in Benchi-Maji zone, Bale eco region and Mexico [16, 35]. This might be due to counseling helps the women to make informed decisions about family planning services utilization [36]. This implies that strengthening
TABLE 3: Knowledge of the respondent on modern contraceptive methods in Metekel zone, Benishangul, Ethiopia, 2019.

\begin{tabular}{|c|c|c|c|}
\hline Variables & Category & Frequency & Percent (\%) \\
\hline \multirow{2}{*}{$\begin{array}{l}\text { Have you ever heard } \\
\text { about modern } \\
\text { contraceptives } \\
\text { method? }\end{array}$} & Yes & 268 & 46.2 \\
\hline & No & 312 & 53.8 \\
\hline \multirow{5}{*}{$\begin{array}{l}\text { Types of modern } \\
\text { family planning } \\
\text { method you know }\end{array}$} & Pills & 119 & 20.4 \\
\hline & Depo-Provera & 158 & 27.1 \\
\hline & Implant & 73 & 12.5 \\
\hline & IUCD & 10 & 1.7 \\
\hline & Condom & 103 & 17.7 \\
\hline \multirow{5}{*}{$\begin{array}{l}\text { From whom do you } \\
\text { get information } \\
\text { on modern } \\
\text { contraceptive } \\
\text { methods }\end{array}$} & Health workers & 319 & 55 \\
\hline & Husband & 17 & 2.9 \\
\hline & Neighbors & 182 & 31.4 \\
\hline & School & 43 & 7.4 \\
\hline & Radio & 7 & 1.2 \\
\hline \multirow{3}{*}{$\begin{array}{l}\text { What sources of } \\
\text { family planning } \\
\text { do you know? }\end{array}$} & Government HFs & 232 & 40 \\
\hline & Private clinic & 76 & 13.1 \\
\hline & Pharmacy & 14 & 2.4 \\
\hline $\begin{array}{l}\text { Do you know } \\
\text { modern }\end{array}$ & Yes & 257 & 44.3 \\
\hline $\begin{array}{l}\text { contraceptives used } \\
\text { to unwanted } \\
\text { pregnancy? }\end{array}$ & No & 323 & 55.7 \\
\hline $\begin{array}{l}\text { Do you know } \\
\text { modern }\end{array}$ & Yes & 237 & 40.9 \\
\hline $\begin{array}{l}\text { contraceptives used } \\
\text { to spacy children? }\end{array}$ & No & 343 & 59.1 \\
\hline $\begin{array}{l}\text { Do you know early } \\
\text { initiation of modern }\end{array}$ & Yes & 224 & 38.6 \\
\hline $\begin{array}{l}\text { contraceptives after } \\
\text { delivery is important }\end{array}$ & No & 356 & 61.4 \\
\hline $\begin{array}{l}\text { Counseling about } \\
\text { modern family } \\
\text { planning method }\end{array}$ & $\begin{array}{l}\text { Yes } \\
\text { No }\end{array}$ & $\begin{array}{l}108 \\
472\end{array}$ & $\begin{array}{l}18.62 \\
81.38\end{array}$ \\
\hline
\end{tabular}

counseling service in the health facility increase the uptakes of modern family planning utilization.

Maternal age was found significantly associated for modern contraceptive utilization specifically from age $\geq 35$ were more likely to use contraceptive than those women whose age 15-24 years. This finding was in line with that of Nepal [24]. This might be due to the fact that women in lower groups (15-24 years) might perceive a low risk of pregnancy. In addition, in this study, the odds of modern contraceptive utilization among women who have primary school level education were 7 times and secondary school level education was 7 times higher than those women who cannot read and write. This might be due to education is one of a key factor for women's empowerment and decide to utilize family planning services compare to noneducated women. 
TABLE 4: Factors associated with modern contraceptive methods utilization among married Gumuz women in Metekel zone, Benishangul Gumuz Ethiopia, 2019.

\begin{tabular}{|c|c|c|c|c|}
\hline \multirow{2}{*}{ Variables } & \multicolumn{2}{|c|}{ Modern contraceptive utilization } & \multirow{2}{*}{ COR $(95 \% \mathrm{CI})$} & \multirow{2}{*}{ AOR (95\% CI) } \\
\hline & Yes & No & & \\
\hline \multicolumn{5}{|l|}{ Age in year } \\
\hline $15-24$ & $8(7.4)$ & $26(5.5)$ & 1 & 1 \\
\hline $25-34$ & $64(59.3)$ & $339(71.8)$ & $0.61(0.26-1.41)$ & $1.50(0.49-4.61)$ \\
\hline$\geq 35$ & $36(33.3)$ & $107(22.7)$ & $1.09(0.45-2.63)$ & $4.67(1.34-16.18)$ \\
\hline \multicolumn{5}{|l|}{ Educational status } \\
\hline Cannot read and write & $60(55.6)$ & $423(89.6)$ & 1 & 1 \\
\hline Able to read and write & $20(18.5)$ & $23(4.9)$ & $6.13(3.17-11.83)$ & $6.4(2.9-13.9)$ \\
\hline Primary school (1-8) & $12(11.1)$ & $7(1.5)$ & $12.08(4.57-31.9)$ & $6.56(2.22-19.38)$ \\
\hline Secondary school (9-12) & $16(14.8)$ & $19(4)$ & $5.93(2.89-12.17)$ & $7.27(3.00-17.61)$ \\
\hline \multicolumn{5}{|l|}{ Parity } \\
\hline$\leq 1$ & $4(3.7)$ & $11(2.3)$ & 1 & 1 \\
\hline $2-4$ & $65(60.2)$ & $306(64.8)$ & $0.58(0.18-1.89)$ & $1.92(0.92-3.98)$ \\
\hline$\geq 5$ & $39(36.1)$ & $155(32.8)$ & $0.54(0.69-0.20)$ & $3.9(0.51-29.46)$ \\
\hline \multicolumn{5}{|l|}{ Counseling on contraceptive } \\
\hline No & $78(16.5)$ & $394(83.5)$ & 1 & 1 \\
\hline Yes & $57(52.8)$ & $51(47.2)$ & $5.64(3.60-8.84)$ & $3.72(2.11-6.56)$ \\
\hline \multicolumn{5}{|l|}{ Knowledge } \\
\hline Poor knowledge & $34(31.5)$ & $346(73.3)$ & 1 & 1 \\
\hline Moderate knowledge & $31(28.7)$ & $58(12.3)$ & $5.43(3.10-9.52)$ & $2.31(1.15-4.46)$ \\
\hline Good knowledge & $43(39.8)$ & $68(14.4)$ & $6.43(3.82-10.81)$ & $4.37(2.38-8.02)$ \\
\hline \multicolumn{5}{|l|}{ Couple discussion } \\
\hline No & $78(72.2)$ & $373(79)$ & 1 & 1 \\
\hline Yes & $30(27.8)$ & $99(21)$ & $1.44(.90-2.33)$ & $1.95(0.51-2.75)$ \\
\hline \multicolumn{5}{|l|}{ Live children } \\
\hline$\leq 1$ & $2(1.9)$ & $8(1.8)$ & 1 & 1 \\
\hline $2-4$ & $70(64.8)$ & $299(63.3)$ & $0.93(0.19-4.50)$ & $1.46(0.05-3.32)$ \\
\hline$\geq 5$ & $36(33.3)$ & $165(35)$ & $0.87(0.17-4.28)$ & $1.44(0.05-3.31)$ \\
\hline
\end{tabular}

\section{Conclusion}

The prevalence of modern contraceptive utilization in the study area was low compared to the national prevalence of the country. Maternal education, maternal ages $(\geq 35)$, knowledge about FP, and counseling on modern contraceptive methods were affecting modern family planning services utilization. Recommendation, for ministry of education, work hard to reach women's educational status at least the primary level.

\section{Data Availability}

The data used to support the findings of this study are included within the article.

\section{Ethical Approval}

The ethical clearance was received from the Bahir Dar University College of Medicine and Health Science ethical and clearance review committee with the ethical protocol number of 02017/18-09. The permission letter was received from
Benishangule Gumuz regional state, Metekel Zone health office bureau, and District health office. Informed verbal consent was taken in every questionnaire for every married Gumuz mother and based on her agreement the data collections took place. Information was provided for all participants about the objective, the purpose or the contents of the study as well as their rights to refusal and discontinuation of the study and reassuring the confidentiality of how to handle and use the data.

\section{Conflicts of Interest}

The authors declare that they have no competing interests.

\section{Authors' Contributions}

AAA initiated and develops the manuscript and performed data analysis. YAB and EM involved equally in the analysis and preparation of the manuscript. All authors read and approved the final manuscript. 


\section{Acknowledgments}

First of all, we would like to thank Bahir Dar University College of Medicine and Health Sciences, School of Public Health. We would also like to thank Metekel Zone District health office staff, health professional they work in the health centers, and health extension workers in the community for their invaluable support through the whole process. Finally, we are also grateful to the supervisors and data collectors who have committed themselves throughout the study period and to all participants who volunteered to participate in this study. Bahir Dar University has funded this research.

\section{References}

[1] J. Tripney, K. Bird, I. Kwan, and J. Kavanagh, The Impact of Post-Abortion Care Family Planning Counselling and Services in Low-Income Countries: A Systematic Review of the Evidence, EPPI-Centre, Social Science Research Unit, Institute of Education, University of London, London, 2011.

[2] R. G. Ponce de Leon, F. Ewerling, S. J. Serruya et al., "Contraceptive use in Latin America and the Caribbean with a focus on long-acting reversible contraceptives: prevalence and inequalities in 23 countries," The Lancet Global Health, vol. 7, no. 2, pp. e227-e235, 2019.

[3] Organization WH, WHO| Family planning/contraception: fact sheet No 351, 2015, Available from:[Last accessed on 2016 Dec 26] Back to cited text. 2017.

[4] Organization WH, Packages of Interventions for Family Planning, Safe Abortion Care, Maternal, Newborn and Child Health, World Health Organization, Geneva, 2010.

[5] J. Cleland, S. Bernstein, A. Ezeh, A. Faundes, A. Glasier, and J. Innis, "Family planning: the unfinished agenda," The Lancet, vol. 368, no. 9549, pp. 1810-1827, 2006.

[6] G. Sedgh, J. Bearak, S. Singh et al., "Abortion incidence between 1990 and 2014: global, regional, and subregional levels and trends," The Lancet, vol. 388, no. 10041, pp. 258-267, 2016.

[7] A. I. Up, Investing in Contraception and Maternal and Newborn Health New York, Guttmacher Institute, New York, 2017.

[8] R. Miller, I. Askew, M. C. Horn, and L. Ndhlovu, Clinic-based family planning and reproductive health services in Africa: findings from situation analysis studies, K. Miller, Ed., Population Council, New York, NY, USA, 1918.

[9] A. Innocent, Y. Sunday, and A. M. Momoh, "Knowledge, attitude and uptake of family planning services among women of reproductive age group attending outpatient clinic at a tertiary health institution in Edo State, Nigeria," Journal of Public Health and Epidemiology, vol. 11, no. 3, pp. 63-70, 2019.

[10] S. K. Sharma, D. R. Ghimire, and N. Pratap, "Ethnic differentials of the impact of family planning program on contraceptive use in Nepal," Demographic Research, vol. 25, pp. 837-868, 2011.

[11] G. M. A. Kibria, S. Hossen, R. A. A. Barsha, A. Sharmeen, S. K. Paul, and S. M. I. Uddin, "Factors affecting contraceptive use among married women of reproductive age in Bangladesh," Journal of Molecular Studies and Medicine Research, vol. 2, no. 1, pp. 70-79, 2016.

[12] N. Peer, N. Morojele, and L. London, "Factors associated with contraceptive use in a rural area in Western Cape Province," South African Medical Journal, vol. 103, no. 6, pp. 406-412, 2013.
[13] P. K. Malalu, K. Alfred, R. Too, and A. Chirchir, "Determinants of use of modern family planning methods: a case of Baringo North District, Kenya," Science journal of public health, vol. 2, no. 5, pp. 424-430, 2014.

[14] I. Alenoghena, S. Yerumoh, and A. Momoh, Knowledge, Attitude and Uptake of Family Planning Services among Women of Reproductive Age Group Attending Outpatient Clinic at a Tertiary Health Institution in Edo State, Nigeria, 2019.

[15] S. S. Belda, M. T. Haile, A. T. Melku, and A. K. Tololu, "Modern contraceptive utilization and associated factors among married pastoralist women in Bale eco-region, Bale Zone, South East Ethiopia," BMC health services research, vol. 17, no. 1, p. 194, 2017.

[16] W. Mekonnen and A. Worku, "Determinants of low family planning use and high unmet need in Butajira District South Central Ethiopia," Reproductive Health, vol. 8, no. 1, p. 37, 2011.

[17] Y. Lakew, A. A. Reda, H. Tamene, S. Benedict, and K. Deribe, "Geographical variation and factors influencing modern contraceptive use among married women in Ethiopia: evidence from a national population based survey," Reproductive Health, vol. 10, no. 1, p. 52, 2013.

[18] T. Tilahun, G. Coene, S. Luchters et al., "Family planning knowledge, attitude and practice among married couples in Jimma Zone, Ethiopia," PLoS ONE, vol. 8, no. 4, article e61335, 2013.

[19] A. A. Medhanyie, A. Desta, M. Alemayehu et al., "Factors associated with contraceptive use in Tigray, North Ethiopia," Reproductive Health, vol. 14, no. 1, p. 27, 2017.

[20] A. Mohammed, D. Woldeyohannes, A. Feleke, and B. Megabiaw, "Determinants of modern contraceptive utilization among married women of reproductive age group in north Shoa zone, Amhara Region, Ethiopia," Reproductive Health, vol. 11, no. 1, p. 13, 2014.

[21] M. Alemayehu, H. Lemma, K. Abrha et al., "Family planning use and associated factors among pastoralist community of afar region, eastern Ethiopia," BMC Women's Health, vol. 16, no. 1, p. 39, 2016.

[22] J. B. Homco, J. F. Peipert, G. M. Secura, V. A. Lewis, and J. E. Allsworth, "Reasons for ineffective pre-pregnancy contraception use in patients seeking abortion services," Contraception, vol. 80, no. 6, pp. 569-574, 2009.

[23] S. A. Adebowale and M. E. Palamuleni, "Determinants of unmet need for modern contraception and reasons for non-use among married women in rural areas of Burkina Faso," African Population Studies, vol. 28, no. 1, pp. 499514, 2014.

[24] J. C. Fotso, C. Izugbara, T. Saliku, and R. Ochako, "Unintended pregnancy and subsequent use of modern contraceptive among slum and non-slum women in Nairobi, Kenya," BMC Pregnancy and Childbirth, vol. 14, no. 1, p. 224, 2014.

[25] P. A. Apanga and M. A. Adam, "Factors influencing the uptake of family planning services in the Talensi District, Ghana," Pan African Medical Journal, vol. 20, no. 1, 2015.

[26] Central Statistical Agency (CSA) [Ethiopia] and ICF, Ethiopia Demographic and Health Survey 2016, CSA and ICF, Addis Ababa, Ethiopia, and Rockville, MD, USA, 2016.

[27] M. Amentie, M. Abera, and M. Abdulahi, "Utilization of Family Planning Services and Influencing Factors among Women of Child Bearing Age in Assosa District, Benishangul Gumuz Regional State, West Ethiopia," Science Journal of Clinical Medicine, vol. 4, no. 3, p. 52, 2015. 
[28] T. B. Kassa, G. Degu, and Z. Birhanu, “Assessment of modern contraceptive practice and associated factors among currently married women age 15-49 years in Farta District, South Gondar zone, North West Ethiopia," Science Journal of Public Health, vol. 2, no. 6, pp. 507-512, 2014.

[29] Central Statistical Agency (CSA) [Ethiopia] and ICF, Mini Ethiopia Demographic and Health Survey 2019, CSA and ICF, Addis Ababa, Ethiopia, and Rockville, MD, USA, 2019.

[30] Kenya National Bureau of Statistics, Ministry of Health/Kenya, National AIDS Control Council/Kenya, Kenya Medical Research Institute, and National Council for Population and Development/Kenya, Kenya Demographic and Health Survey 2014, CSA and ICF, Nairobi, Kenya, and Rockville, MD, USA, 2015.

[31] C. K. Ajaero, C. Odimegwu, I. D. Ajaero, and C. A. Nwachukwu, "Access to mass media messages, and use of family planning in Nigeria: a spatio-demographic analysis from the 2013 DHS," BMC Public Health, vol. 16, no. 1, p. 427, 2016.

[32] Health MO, Costed implementation plan for family planning in ethiopia, Federal democratic republic of ministory of Health, 2015-2020.

[33] M. Nyaga, Ethnicity and Contraceptive Use in Kenya, 2016, http:// wiredspace.wits.ac.za/bitstream/handle/10539/21843/ ETHNICITY_REPORT\%20PDF.pdf?sequence=1\&isAllowed=y.

[34] A. Gueye, I. S. Speizer, M. Corroon, and C. C. Okigbo, "Belief in family planning myths at the individual and community levels and modern contraceptive use in urban Africa," International Perspectives on Sexual and Reproductive Health, vol. 41, no. 4, pp. 191-199, 2015.

[35] S. L. Barber, "Family planning advice and postpartum contraceptive use among low-income women in Mexico," International Family Planning Perspectives, vol. 33, no. 1, pp. 6-12, 2007.

[36] The ACQUIRE Project, Counseling for effective use of family planning participant handbook, EngenderHealth/The ACQUIRE Project, New York, 2008. 